\title{
Pengendalian Sikap Lateral Pesawat Flying Wing Menggunakan Metode LQR
}

\author{
Try Susanto \\ Program Studi Informatika \\ Fakultas Teknik \& Ilmu Komputer \\ Lampung Indonesia \\ try_susanto@teknokrat.ac.id
}

\author{
Syaiful Ahdan \\ Program Studi Teknologi Informasi \\ Fakultas Teknik \& Ilmu Komputer \\ Lampung, Indonesia \\ syaifulahdan@teknokrat.ac.id
}

\begin{abstract}
Unnamed Aerial Vehicle (UAV) technology of drone is widely used to carry out various mission such as photography, disaster monitoring, and area mapping. However, crash can be caused by environmental disturbances that hinders the completion of the mission. Moreover, an automatic control system is needed to handle this. In this study, the LQR control method is used to control the eleven and pitch angle so that the drone is able to maintain a stable lateral attitude. This control method has a fast and strong response in reaching a point of balance. Based on the test results, it show that the LQR control method applied is able to control the pitch angle and is able to make the drone maintain a lateral attitude, as evidenced by the disturbance at a pitch $20^{\circ}$ the drone is able to maintain a lateral attitude with overshoot of $4.23^{\circ}$, risetime of 0,7 second, settling time of 1,2 second with a steady state error trend of $\mathbf{0 , 7 8}$
\end{abstract}

Keywords-LQR Control, Lateral Atitude, Steady State Error

\section{PENDAHULUAN}

Teknologi Unnamed Aerial Vehicle (UAV) atau pesawat tanpa awak semakin berkembang dengan sering meningkatnya penggunaan diberbagai bidang. Pesawat tanpa awak dapat digunakan untuk melakukan misi fotografi, pemantauan bencana, dan pemetaaan wilayah. Dalam menjalankan misinya, pesawat tanpa awak dapat dikendalikan secara manual maupun secara mandiri dengan mode autopilot. Pengendalian secara manual dilakukan oleh operator dengan menggunakan remote control, sedangkan pengendalian secara autopilot dengan memanfaatkan sensor yang terpasang pada sistem pesawat [1][2].

Salah satu tipe pesawat tanpa awak yang banyak digunakan adalah jenis pesawat flying wing. Jenis pesawat ini memiliki sayap tetap berbentuk segitiga yang dilengkapi dua buah servo dan tidak memiliki ekor (tailless) sehingga konfigurasinya sangat sederhana. Kontrol surface dari pesawat jenis ini terdiri dari elevon (elevator aileron). Pesawat jenis ini mampu terbang secara efektif dengan kemampuannya gliding di udara, selain itu pesawat ini mampu menjelajah jauh sekaligus membawa muatan didalamnya [3][4].
Beberapa kondisi yang dihindari oleh pesawat ketika terbang menjalankan misinya agar tidak terjadi crash, salah satunya adalah stall. Stall adalah kondisi sudut serang (angle of attack) pesawat meningkat melebihi titik tertentu yang menyebabkan gaya angkat menjadi berkurang [5]. Sudut kritis yang dapat menyebabkan stall pada pesawat adalah 25 derajat. Kondisi ini menyebabkan pesawat mengalami spinning (berputar) terhadap sumbu lateral dan sumbu longitudinal. Ketika kondisi ini terjadi, perlu waktu yang lama untuk pesawat memulihkan kondisi ini [6].

Proses pengendalin pesawat tidak menjadi masalah ketika terbang secara manual oleh pilot, namun ketika terbang secara autopilot pesawat dituntut untuk mampu menjaga kestabilansikap sehingga mampu terbang menjalankan misinya dengan baik [5]. Salah satu faktor penting dalam mengendalikan kestabilan terbang adalah pengendalian sikap lateral. Sikap lateral pesawat terletak pesawat terletak pada sumbu melintang dan pergerakan pada sumbu ini disebut dengan gerak pitching. Gerak pitching adalah gerakan hidung pesawat keatas dan kebawah. Gerakan pitch pada sayap di peroleh dengan mengatur elevon ke posisi yang sama [7][8].

Penelitian tentang pengendalian sikap lateral pada pesawat tak berawak telah dilakukan dengan menerapkan metode kendali PID oleh [9], metode kendali tersebut mampu mengurangi overshoot pada sistem namum menghasilkan rise time yang besar yang mengakibatkan respon menjadi lebih lambat. Kontroler proporsional pernah diterapkan oleh [10], tetapi menghasilkan error yang relative besar. Pengendalian gerak pitch sangat penting karena dapat mempengaruhi sikap lateral pesawat dalam mencapai keseimbangan atau kondisi datar pada pesawat. Oleh karena itu dibutuhkan sistem kendali yang cepat dan kuat untuk mencapai titik kestabilan menjadi sangat penting. Salah satu metode yang memiliki kemampuan tersebut adalah metode kendali LQR [11]. Mengacu penelitian yang dilakukan oleh [12], ia menerapkan metode kendali LQR untuk kestabilan sikap pada quadrotor. Metode tersebut mampu membuat wahana memiliki sikap terbang yang baik. Berdasarkan keunggulan yang dimiliki oleh metode kendali LQR tersebut, penelitian ini menerapkan 


\section{Pengendalian Sikap Lateral Pesawat Flying Wing Menggunakan Metode LQR}

metode kendali LQR untuk menangani sikap lateral pada pesawat flying wing.

\section{PEMODELAN FLYING WING}

Penelitian ini menggunakan tipe pesawat tipe flying wing sebagai objek penelitannya. Flying wing adalah pesawat tanpa awak yang memiliki sayap berbentuk segitiga dan dilengkapi dua buah servo serta tidak memiliki ekor. Model dinamika pesawat flying wing ditunjukkan pada gambar 1

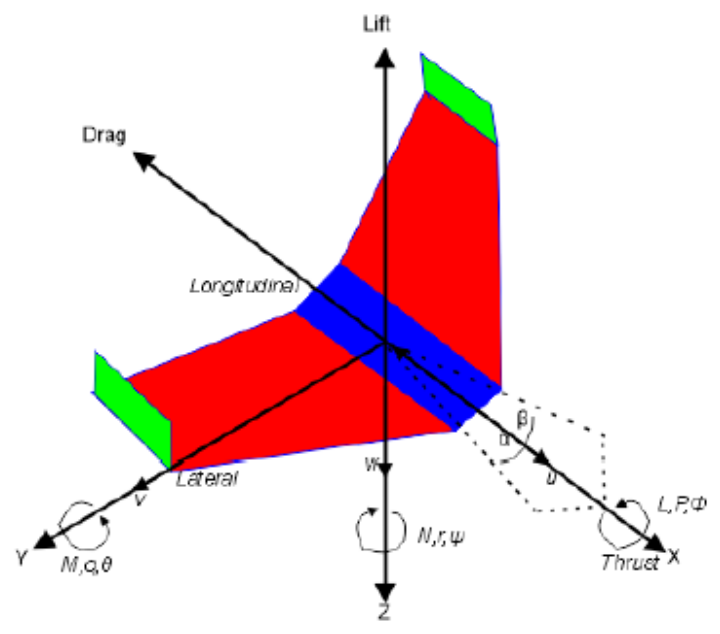

Gambar 1. Dinamika gerak pesawat flying wing

\section{A. Gerak Translasi}

Penentuan gerak translasi pesawat menggunakan hukum Newton-Euler didasarkan pada hukum kedua Newton

$$
\begin{gathered}
\sum F=m a \\
\sum F=F+F_{\text {gravitasi }} \\
\sum F=m \frac{d}{d t} v_{T}=m \frac{d}{d t}+\left(\omega x v_{T}\right)
\end{gathered}
$$

Vektor kecepatan linier dan angular total dihitung menggunakan (4) dan (5),

$$
\begin{gathered}
v_{T}=i U+j V+k W \\
\omega=i P+j Q+k R
\end{gathered}
$$

Dengan menggunakan aturan perkalian matriks, maka gaya yang bekerja dapat dituliskan menjadi (6)

$$
\omega x v_{T}=\left[\begin{array}{ccc}
i & j & k \\
P & Q & R \\
U & V & W
\end{array}\right]=(Q W-V R)+(U R-P W)+(P V-U Q)
$$

Karena adanya pengaruh gaya gravitasi pada setiap sumbu, maka persamaan gaya menjadi,

$$
\begin{gathered}
X=(U+Q W-V R+g \sin \theta) \\
Y=(V+U R-P W-g \cos \theta \sin \phi) \\
Z=(W+P V-U Q+g \cos \theta \cos \phi)
\end{gathered}
$$

\section{B. Gerak Rotasi}

Pada pesawat tidak hanya terjadi gerak translasi saja, tetapi juga mengalami gerak rotasi. Gerak rotasi ini menyebabkan terjadi momentum anguler. Momentum anguler adalah momentum suatu benda yang berotasi pada porosnya hingga membentuk sudut tertentu. Momentum anguler pada pesawat dituliskan pada (10),

$$
H=I \omega
$$

Sedangkan torsi yang bekerja pada pesawat dituliskan pada (11),

$$
M=I \frac{d}{d t}(\omega+\omega x \omega)+\omega x H
$$

Karena $\omega \mathrm{x} \omega=0$, maka persamaan diatas menjadi (12),

$$
\frac{d}{d t} \omega=i P+j Q+k R
$$

Dengan menggunakan aturan matriks, maka menjadi (13),

$$
\omega \times H=\left[\begin{array}{lll}
i & j & k \\
P & Q & R \\
h_{x} & h_{y} & h_{z}
\end{array}\right]
$$

Momentum anguler yang bekerja pada pesawat dapat dituliskan pada matriks menjadi:

$$
H=\left[\begin{array}{ccc}
I_{x x} & -I_{y y} & -I_{z z} \\
-I_{x y} & I_{y y} & -I_{y z} \\
-I_{x y} & -I_{y z} & I_{z z}
\end{array}\right]
$$

dengan $h_{x}, h_{y}, h_{z}$ adalah

$$
\begin{gathered}
h_{x}=-I_{x x} P-I_{x y} Q-I_{x z} R \\
h_{y}=-I_{x x} P+I_{y y} Q-I_{y z} R \\
h_{z}=-I_{x z} P-I_{y z} Q+I_{z z} R
\end{gathered}
$$

maka

$$
\text { (6) } \frac{d}{d t} \omega=\left[\begin{array}{ccc}
I_{x x} \dot{P} & -I_{y y} \dot{Q} & -I_{z z} \dot{R} \\
-I_{x y} \dot{P} & I_{y y} \dot{Q} & -I_{y z} \dot{R} \\
-I_{x y} \dot{P} & -I_{y z} \dot{Q} & I_{z z} \dot{R}
\end{array}\right]
$$

Secara umum, badan pesawat simetri terhadap bidang $\mathrm{XZ}$, sehingga $I_{x y}=I_{y z}=0$, maka momen roll, pitch dan yaw dapat dituliskan menjadi;

$$
M_{x}=I_{x x} \dot{P}-(\dot{R}+P Q)+\left(I_{z z}-I_{y y}\right)
$$




$$
\begin{gathered}
M_{y}=I_{Y Y} \dot{Q}-(P 2+R 2)+\left(I_{x x}-I_{z z}\right) \\
M_{z}=I_{z z} \dot{R}-I_{x z}-I_{x x}+R Q I_{x z}
\end{gathered}
$$

\section{METODE KONTROLER}

Metode LQR merupakan kontrol yang model dan bentuk kontrolernya berupa linier. Persamaan (22) dan (23) merupakan persamaan sistem linier.

$$
\begin{gathered}
x=A x+B u \\
u=C x
\end{gathered}
$$

Selain itu, metode ini juga menggunakan hukum umpan balik keadaan

$$
u=-K x
$$

Model rancangan sistem kendali pesawat flying wing diperoleh dengan cara menurunkan persamaan (7) hingga persamaan (9), yang merupakan persamaan torsi pada pesawat. Penyesuaian variabel untuk model pada penelitian ini tertulis dalam Table 1

Tabel 1. Penyesuaian variabel

\begin{tabular}{|c|c|c|}
\hline Variabel awal & $\begin{array}{c}\text { Variabel } \\
\text { Penyesuaian }\end{array}$ & Keterangan \\
\hline $\mathrm{L}$ & $\tau_{1}$ & Torsi roll \\
\hline $\mathrm{M}$ & $\tau_{2}$ & Torsi pitch \\
\hline $\mathrm{P}$ & $\omega_{\phi}$ & Kecepatan sudut roll \\
\hline $\mathrm{Q}$ & $\omega_{\theta}$ & Kecepatan sudut pitch \\
\hline
\end{tabular}

Berdasarkan Tabel 1, maka persamaan gerak rotasi pesawat terhadap sumbu $\mathrm{x}$ dan $\mathrm{y}$ dapat dituliskan menjadi,

$$
\begin{aligned}
& \tau_{1}=I_{x x} \dot{p}+\left(I_{x z}-I_{y y}\right) \omega_{\theta} r \\
& \tau_{2}=I_{y y} \dot{q}+\left(I_{x x}-I_{z z}\right) \omega_{\phi} r
\end{aligned}
$$

Dimana $I_{x x}$ adalah inersia pada sumbu x pesawat, $I_{y y}$ adalah inersia pada sumbu $\mathrm{y}, \quad p$ adalah percepatan sudut roll, $q$ adalah percepatan sudut pitch, dan $\mathrm{r}$ adalah yaw rate. Parameter sistem yang digunakan untuk pengendalian kestabilan lateral pesawat melibatkan 8 state, yaitu:

- Posisi x kecepatan translasi sumbu x $\left(v_{x}\right)$

- Posisi y dan kecepatan trasnlasi sumbu y $\left(v_{y}\right)$

- Sudut roll $(\phi)$ dan kecepatan sudut roll $\left(\omega_{\phi}\right)$

- Sudut pitch $(\theta)$ dan kecepatan sudut pitch $\left(\omega_{\theta}\right)$

Dengan demikian, bentuk statet space pesawat flying wing dapat dituliskan menjadi (27)

$$
\begin{gathered}
{\left[\begin{array}{c}
U \\
\dot{U} \\
V \\
\dot{V} \\
P \\
\dot{P} \\
Q \\
\dot{Q}
\end{array}\right]=\left[\begin{array}{lllllllc}
0 & 1 & 0 & 0 & 0 & 0 & 0 & 0 \\
0 & 0 & 0 & 0 & 0 & 0 & 0 & 0 \\
0 & 0 & 0 & 1 & 0 & 0 & 0 & 0 \\
0 & 0 & 0 & 0 & 0 & 0 & 0 & 0 \\
0 & 0 & 0 & 0 & 0 & 1 & 0 & 0 \\
0 & 0 & 0 & 0 & 0 & 0 & 0 & \frac{\left(I_{y y}-I_{z z}\right) r}{I_{x x}} \\
0 & 0 & 0 & 0 & 0 & 0 & 0 & 1 \\
0 & 0 & 0 & 0 & \frac{I_{z z}-I_{x x}}{I_{y y}} & 0 & 0 & 0
\end{array}\right]\left[\begin{array}{c}
x \\
v_{x} \\
y \\
v_{y} \\
\phi \\
\omega_{\phi} \\
\theta \\
\omega_{\theta}
\end{array}\right]+\left[\begin{array}{cccc}
0 & 0 & 0 & 0 \\
\frac{1}{m} & 0 & 0 & 0 \\
0 & 0 & 0 & 0 \\
0 & \frac{1}{m} & 0 & 0 \\
0 & 0 & 0 & 0 \\
0 & 0 & \frac{1}{I_{x x}} & 0 \\
0 & 0 & 0 & 0 \\
0 & 0 & 0 & \frac{1}{I_{y y}}
\end{array}\right]\left[\begin{array}{c}
F_{x} \\
F_{y} \\
L \\
M
\end{array}\right]} \\
\dot{X}= \\
\dot{x}
\end{gathered}
$$

Persamaan (28) hingga (30) digunakan untuk menghitung inersia di masing-masing sumbu

$$
\begin{aligned}
& I_{x x}=\frac{1}{12} m\left(b^{2}+c^{2}\right) \\
& I_{y y}=\frac{1}{12} m\left(a^{2}+b^{2}\right) \\
& I_{z z}=\frac{1}{12} m\left(a^{2}+c^{2}\right)
\end{aligned}
$$

Rancangan diagram sistem kendali LQR seperti pada gambar 2

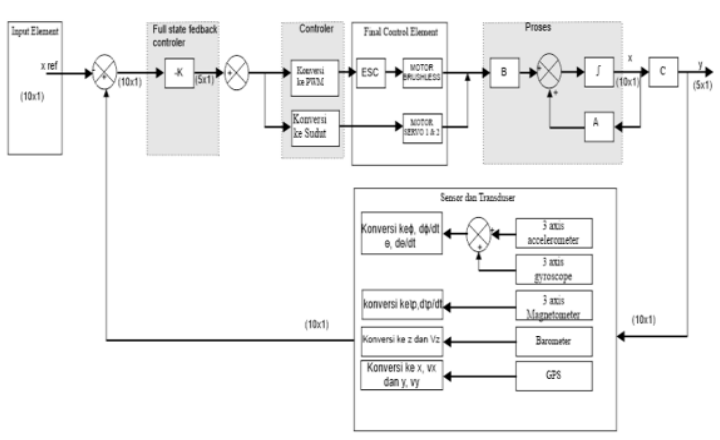

Gambar 2. Rancangan Digram Blok Sistem

Metode kendali LQR bekerja berdasarkan pembobotan matriks $Q$ dan $R$ untuk mendapatkan nilai $K$ terbaik, yang berpengaruh kepada respon sistem sesuai dengan spesfikasi yang di inginkan. Nilai $Q$ berbanding lurus dengan nilai $Q$ berbanding lurus dengan nilai variabel bantu dari persamaan riccati $(\mathrm{P})$ untuk memperoleh nilai $K$. pembobotan nilai $Q$ dan $R$ dimulai dari 1, akan ditambah dan dikurang sesuai dengan respon sistem [13]. Konstanta $Q$ dan $R$ memiliki fungsi yang berlawanan, apabila nilai $R$ besar, maka nilai umpan balik menjadi tidak mempengaruhi sistem, maka dari itu nilai matrix $R$ diberi nilai 1. Metode kendali LQR ini memiliki kekhususan sebagai metode kendali yang digunakan untuk regulator, sehingga jika sistem ingin merubah state maka perlu diberikan state referensi $\left(x_{\text {ref }}\right)$. State referensi ini berguna untuk sistem mempertahankan kondisinya pada posisi tertentu.

$$
\dot{x}=A x+\left(-K\left(x-x_{r e f}\right)\right.
$$




\section{Pengendalian Sikap Lateral Pesawat Flying Wing Menggunakan Metode LQR}

\section{HASIL DAN PEMBAHASAN}

Pesawat tanpa awak yang digunakan pada penelitian ini adalah pesawat jenis flying wing. Sistem peenggerak pesawat menggunakan motor brushless dan propeller sebagai pendorong. Sedangkan sistem pengendali gerakan naik, turun, belok kiri dan kanan menggunakan elevon pada masing-masing sayapnya.

Sebelum dilakukan pengujian sistem, terlebih dahulu dilakukan pembobotan konstantan $Q$ yang digunakan untuk mendapatkan nilai umpan balik $K$. Pembobotan konstanta $Q$ terbaik ditandai dengan pesawat flying wing mampu terbang dengan stabil di tandai dengan besar sudut pitch mendekati $0^{\circ}$. Hasil pembobotan nilai $Q$ dengan umpan balik (gain) $K$ yang menghasilkan respon terbaik disajikan pada tabel 2 .

Tabel 2. Konversi $Q_{\theta}$ dan $Q_{\omega \theta}$ ke gain K

\begin{tabular}{|ccccccc|cc}
\hline \multicolumn{8}{c|}{$\mathrm{Q}$} & \multicolumn{8}{c|}{$\mathrm{K}$} \\
\hline$\left[\begin{array}{cccccccc}0 & 0 & 0 & 0 & 0 & 0 & 1,69 & 0 \\
0 & 0 & 0 & 0 & 0 & 0 & 0 & 12,49\end{array}\right]\left[\begin{array}{cccccccc}0 & 0 & 0 & 0 & 0 & 0 & 1,33 & 6,6\end{array}\right]$ \\
\hline
\end{tabular}

Nilai $Q_{\theta}$ terbaik yang di peroleh dari pembobotan adalah 1,69 dan $Q_{\omega \theta}$ adalah 12,49. Berdasarkan hasil pembobotan $Q_{\theta}$ menghasilkan gain $\mathrm{K}$ sebesar 1,33 mampu membuat pesawat terbang stabil dan mendekati nilai referensi (setpoint) $0^{\circ}$. Penguatan nilai $Q$ berbanding lurus dengan perubahan nilai sudut dan mempengaruhi respon pesawat dalam mempertahankan sikap. Semakin besar nilai K, maka semakin cepat respon sistem dalam memperbaiki sikap menuju setpoint, namun dapat menghasilkan overshoot yang cukup besar. Sebaliknya, jika nilai $K$ kecil, maka respon sistem untuk memperbaiki sikap menuju setpoint semakin lambat.

Pengujian gerak lateral pesawat dilakukan dengan memberikan gangguan sebesar $20^{\circ}$ pada sudut pitch. Sebanyak 3 kali percobaan. Ketika diberikan gangguan, pesawat mulai menyimpang dari setpoint dan terjadilah gerak pitching ke atas dan ke bawah, pergerakan tersebut merupakan multi overshoot yang di alami oleh pesawat. Hasil pengujian sistem disajikan pada Tabel 3.

Tabel 3. Karakteristik Respon Sistem

\begin{tabular}{|c|c|c|c|c|}
\hline \multirow{2}{*}{ Respon Sistem } & \multicolumn{5}{|c|}{ Hasil } \\
\cline { 2 - 5 } & Uji 1 & Ujit 2 & Uji 3 & $\begin{array}{c}\text { Spesfikasi } \\
\text { Minimum }\end{array}$ \\
\hline Rise Time (tr) & 0.8 & 0.7 & 0.86 & $<1 \mathrm{~s}$ \\
\hline Settling Time (ts) & 1.7 & 1.2 & 1.3 & $<3 \mathrm{~s}$ \\
\hline Overshoot & 4.30 & 4.23 & 4.43 & $<4.5^{0}$ \\
\hline Undershoot & 0.7 & 0.3 & 0.5 & $>-4.5^{0}$ \\
\hline $\begin{array}{c}\text { Steady State } \\
\text { Error }\end{array}$ & 0.88 & 0.78 & 0.85 & $\pm 4.5^{0}$ \\
\hline
\end{tabular}

Berdasarkan Table 3, secara keseluruhan pesawat memiliki karakteristik respon yang memenuhi spesfikasi minimum dengan hasil terbaik pada pengujian ke dua. Gambar 3 menampilkan grafik analisa respon sistem terbaik.

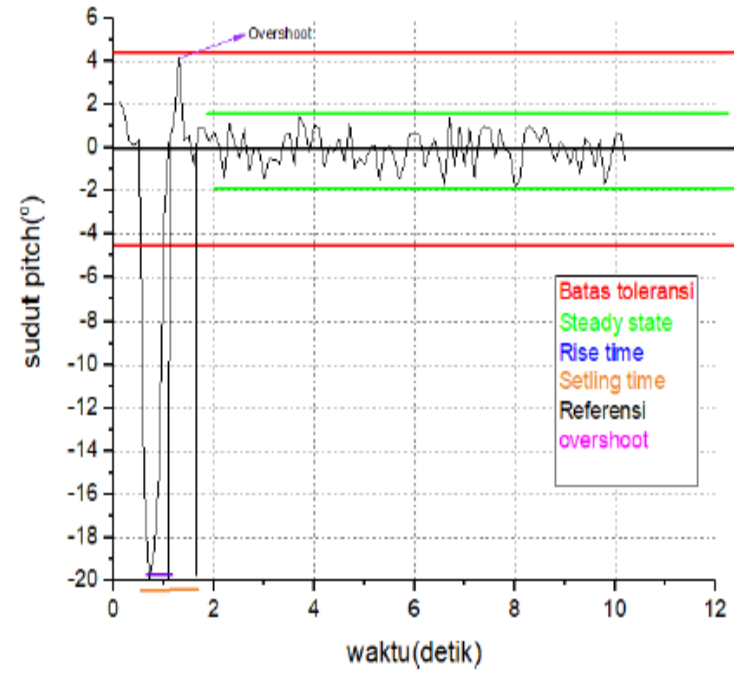

Gambar 3. Karakteristik gerak lateral

Berdasarkan Gambar 3, terlihat pesawat mengalami penyimpangan dari setpoint dan terjadi gerak pitching. Pengujian tersebut menghasilkan puncak overshoot sebesar $4,23^{\circ}$ dengan rise time 0,7 detik. Semakin besar nilai pembobotan $Q_{\theta}$ maka semakin besar pula perubahan sudut yang dihasilkan. Selain itu, perubahan kecepatan sudut juga berperan penting untuk pesawat mencapai titik kestabilan. Semakin kecil pembobotaan $Q_{\omega \theta}$ maka perubahan kecepatan sudut juga semakin kecil dan menyebabkan pesawat memerlukan waktu yang lebih lama untuk menuju setpoint. Perubahan kecepatan sudut juga berfungsi untuk meredam multi overshoot yang terjadi, sehingga diperlukan pembobotan $Q_{\omega \theta}$ terbaik untuk mendapatkan respon pesawat yang sesuai dengan spesfikasi kebutuhan sistem. Waktu yang diperlukan pesawat untuk menuju setpoint setelah terjadinya overshoot sebesar 1,2 detik. Dengan menerapkan metode kendli LQR, gangguan yang diterima sistem mampu di minimalisir dan berhasil mempertahankan sikap dengan kecendrungan steady state error sebesar $0,78^{\circ}$.

Pada Gambar 3 terlihat sistem mengalami osilasi setelah sistem steady. Osilasi pada sistem tersebut merupakan critical stable yang dialami oleh sistem. Sistem akan terus berosilasi dan memiliki kecendrungan error mendekati batas atas maupun batas bawah, dan masih dalam batas toleransi yaitu tidak melebihi $\pm 4,5^{\circ}$. Nilai error yang terjadi tersebut di jumlahkan lalu dicari nilai rata-rata untuk mendapatkan steady state error.

Berdasarkan pengujian yang telah dilakukan tersebut, membuktikan penerapan metode kendali LQR mampu mengendalikan sudut pitch dan meminimalisir gangguan yang terjadi pada pesawat, sehingga mampu membuat pesawat terbang dengan baik mempertahankan kestabilan sikap lateral. 


\section{Pengendalian Sikap Lateral Pesawat Flying Wing Menggunakan Metode LQR}

\section{KESIMPULAN}

Dari hasil pengujian sistem yang telah dilakukan dapat disimpulkan bahwa penerapan metode kendali LQR mampu membuat pesawat flying wing mempertahankan sikap lateral, terbukti ketika diberikan gangguan pada sudut pitch sebesar $20^{\circ}$ pesawat mampu kembali ke posisi semula. Pesawa flying wing mampu mempertahankan sikap lateral dengan kecendrungan steady state error sebesar $0,78^{\circ}$ dengan batas atas $1,26^{\circ}$ dan batas bawah $-1,74^{\circ}$ didalam batas toleransi yaitu $\pm 4,5^{\circ}$. Respon sistem tersebut telah memenuhi spesifikasi kebutuhan sistem yang diinginkan, yakni dengan rise time 0,7 detik, settling time 1,2 detik, overshoot dengan 4,23. Untuk penelitian selanjutnya, perlu ditambahkan pengendalian sikap longitudinal agar mendapatkan kestabilan pesawat yang lebih baik.

\section{UCAPAN TERIMA KASIH}

Direktorat Riset dan Pengabdian Masyarakat Direktorat Jenderal Penguatan Riset dan PengembanganKementrian Riset, Teknologi, dan Pendidikan tinggi Nomor : 839/SP2H/LT/MONO/LL2/2020.

\section{DAFTAR PUSTAKA}

[1] P. Tanpa, A. Menggunakan, P. S. Ardiantara, R. Sumiharto, and S. B. Wibowo, "Purwarupa Kontrol Kestabilan Posisi dan Sikap pada Pesawat Tanpa Awak Menggunakan IMU dan Algoritma Fusion Sensor Kalman Filter," IJEIS (Indonesian J. Electron. Instrum. Syst., vol. 4, no. 1, pp. 25-34, 2014, doi: 10.22146/ijeis.4219.

[2] D. B. Widyantara, R. Sumiharto, and S. B. Wibowo, "Purwarupa Sistem Kendali Kestabilan Pesawat Tanpa Awak Sayap Tetap Menggunakan Robust PID," IJEIS (Indonesian J. Electron. Instrum. Syst., vol. 6, no. 2, p. 139, 2016, doi: 10.22146/ijeis.15260.

[3] S. Markin,"Multiple Simultaneous Spesfication Attitude Control of a Mini Flying-Wing Unnamed Aerial Vehicle" , Graduate Departmen of Toronto, 2010.

[4] E. Irmawan, P. Mulyono, P. Studi, T. Dirgantara, S. Tinggi, and T. Kedirgantaraan, "KENDALI FUZZYPID PADA SIKAP LONGITUDINAL DAN SIKAP LATERAL PESAWAT TANPA AWAK FIXED WING," vol. 2, no. 2, pp. 1-7, 2018.

[5] E. Irmawan and E. E. Prasetiyo, "Kendali Adaptif Neuro Fuzzy PID untuk Kestabilan Terbang Fixed Wing UAV ( Adaptive Control of Neuro Fuzzy PID for Fixed Wing UAV," vol. 9, no. 1, pp. 73-78, 2020.

[6] A. Crasta and S. A. Khan, "EFFECT OF ANGLE OF INCIDENCE ON STABILITY DERIVATIVES OF A WING," pp. 1-6, 1978.

[7] A. P. Wijaya, A. Triwiyatno, and B. Setiyono, "Perancangan Self Balancing Pitch Control Dengan Metode Kontrol Fuzzy Pada Unmanned Aerial Vehicle Fixed Wing," Peranc. Self Balanc. Pitch Control Dengan Metod. Kontrol Fuzzy Pada Unmanned Aer. Veh. Fixed Wing, vol. 17, no. 4, pp. 162-171, 2015, doi: 10.12777/transmisi.17.4.162-171.
[8] C. P. R. Tuuk et al., "Implementasi Pengendali PID Untuk Kestabilan Posisi Terbang Wahana Tanpa Awak," vol. 7, no. 1, pp. 53-62, 2018.

[9] M. Fajar and O. Arifianto, "Perancangan Autopilot Lateral-Directional Pesawat Nirawak LSU-05", Jurnal Teknologi Dirgantara, vol. 05, pp. 93-104, 2017.

[10] A. Hadi, "Desain Kontroler Proporsional Modifikasi pada Motor Servo,” vol. 06, no. 2, pp. 59-62, 2019.

[11] L. M. Argentim, P. E. Santos, and R. A. Aguiar, "PID , LQR and LQR-PID on a Quadcopter Platform."

[12] O. A. Dhewa, A. Dharmawan, and T. K. Priyambodo, "Model of Linear Quadratic Regulator ( LQR ) Control Method in Hovering State of Quadrotor," vol. 9, no. 3, pp. 135-143, 1843.

[13] A. B. Zakaria and A. Dharmawan, "Sistem Kendali Penghindar Rintangan Pada Quadrotor Menggunakan Konsep Linear Quadratic," IJEIS (Indonesian J. Electron. Instrum. Syst., vol. 7, no. 2, p. 219, 2017, doi: 10.22146/ijeis.25503.
Copyright @2016 PROtek : Jurnal Ilmiah Teknik Elektro lisensi Creative Commons Attribution 4.0 International Licensi 